\title{
OPERAÇÃO LIMPAOCA- SUBSÍdIOS PARA A POLÍTICA NACIONAL DE RESÍDUOS SÓLIDOS NA ESTAÇÃO ECOLÓGICA (ESEC) DA GUANABARA, RJ
}

\author{
Maria das Graças Silveira Bispo ${ }^{1}$ \\ Rodrigo Gaião Brault de Miranda ${ }^{1}$
}

\section{RESUMO}

Aliada à necessidade de conservação de áreas de manguezal em Unidades de Conservação (UCs) e de integração com diferentes setores da sociedade, em especial com as comunidades de pescadores e catadores de caranguejo, foi realizada a OPERAÇÃO LIMPAOCA de coleta de resíduos sólidos em área de manguezal. Participaram das atividades 13 pecadores e catadores de caranguejo, sendo coletados $2.850 \mathrm{~kg}$ de resíduos totais (2.266 kg de plásticos, $324 \mathrm{~kg}$ de isopor, $167 \mathrm{~kg}$ de vidros, $77 \mathrm{~kg}$ de couro e afins e $16 \mathrm{~kg}$ de metais), num período de 22 horas. Todo esse material estava sendo carreado pelas águas do Rio Guaxindiba para a Baía de Guanabara. Sem levar em conta a extensão da área de atuação, a coleta diária foi de $129,5 \mathrm{~kg} / \mathrm{hora} / 13$ participantes e média de $9,9 \mathrm{~kg} /$ coletor. Materiais plásticos predominaram, assim como citado em outras referências. Resíduos de isopor vieram em seguida, mas devido ao seu grande volume e baixo peso, sua presença foi significativa. Vidro (100 \% de lâmpadas) foi o terceiro colocado seguido do grupo mais heterogêneo (couro e afins) e, por fim, o de metais. O material coletado foi avaliado em $\mathrm{R} \$ 4.425,75$. Foram desperdiçados no ambiente $2.590 \mathrm{~kg}$ de petróleo e $217 \mathrm{~kg}$ de areia, respectivamente, porque os plásticos e vidro não voltaram à cadeia produtiva, via reciclagem. A Operação LIMPAOCA tem um caráter inovador, por se tratar de ação de Política Pública, com abordagem socioeducativa (PNEA) em área de UCs.

Palavras chave: Resíduos sólidos no mangue; limpeza manguezal; balanço ecológico.

\section{ABSTRACT}

Coupled with the need for conservation of mangrove areas in protected areas and integration with different sectors of society, particularly with the communities of fishermen and crab pickers, was held LIMPAOCA OPERATION collection of solid waste in the mangrove area. Thirteen fishermen and crab pickers participated in the activities, being collected 2850 kilograms of total waste (plastics - $2266 \mathrm{~kg}$, styrofoam - $324 \mathrm{~kg}$, glasses - $167 \mathrm{~kg}$, leather and related products - $77 \mathrm{~kg}$ of and metal $-16 \mathrm{~kg}$ ), over 22 hours. All this material was being taken by Guaxindiba River waters for Guanabara Bay. Regardless of the extent of the coverage area, the daily collection was $129.5 \mathrm{~kg} /$ hour / 13 participants and an average of 9.9 $\mathrm{kg} /$ collector. Plastic materials predominated, as quoted in other references. Styrofoam waste followed, but due to its large volume and low weight, its presence was significant. Glass (100\% lamps) was added followed by the third heterogeneous group (leather and the like), and finally the metal. The collected material was valued at $\mathrm{R} \$ 4,425.75$. They were wasted in $2590 \mathrm{~kg}$ of oil environment and $217 \mathrm{~kg}$ of sand, respectively, because the plastics and glass have not returned to the production chain, via recycling. The LIMPAOCA Operation has an innovative character, because it is acting Public Policy, with socio-educational approach (PNEA) in UCs area.

Keywords: Solid waste in mangrove; mangrove cleanup; ecological balance

ONG Guardiões do Mar. Contato E-mail: gracabispo09@gmail.com 


\section{INTRODUÇÃO}

A Política Nacional dos Resíduos Sólidos (Lei 12.305/10) propicia o enfrentamento integrado de problemas ambientais, sociais e econômicos ocasionados pelo manejo incorreto de recicláveis. Duas importantes vertentes temáticas estão contidas em sua proposta: a destinação ambientalmente adequada dos rejeitos e a formação da cadeia de reciclagem² ${ }^{2}$. Além disso, a responsabilidade compartilhada do manejo dos resíduos sólidos contribuiu para a criação dessa ação piloto em uma área de manguezal.

Os manguezais estão em $8 \%$ das costas do planeta e $25 \%$ das regiões tropicais, num total de $181.077 \mathrm{~km} 2$, sendo que o Brasil possui cerca de $25.000 \mathrm{Km}^{2}$ (ALMEIDA et al., 2013). O descarte incorreto de resíduos sólidos são os principais responsáveis pela perda da estética ambiental e risco para a saúde dos usuários e biota desses ecossistemas costeiros (ARAÚJO e COSTA 2007 a e b).

No Estado do Rio de Janeiro, na região leste da Baía de Guanabara foi criada a Área de Proteção Ambiental (APA) de Guapi-Mirim, com o objetivo de proteger os manguezais. A região está situada na foz dos Rios Iriri, Roncador, Guapi-Mirim e Imboaçu, abrangendo os Municípios de Magé, Itaboraí e São Gonçalo. Dentro dessa região encontra-se a ESEC Guanabara, criada em 15 de fevereiro de 2006, localizada nos Municípios de Guapimirim e Itaboraí (RJ), com o objetivo de preservação dos remanescentes de manguezal da Baía da Guanabara e sua fauna e flora associada, bem como a realização de pesquisas científicas ${ }^{3}$. Ela faz parte da Reserva da Biosfera da Mata Atlântica (RBMA), sendo integrante de sua zona núcleo. Protege em seus limites feições primárias de manguezal altamente preservadas e caracteriza-se como área prioritária para salvaguarda das espécies vegetais e animais características desse ecossistema.

Desde 2011 a sede compartilhada da ESEC Guanabara/APA Guapi-Mirim é reconhecida como posto avançado da RBMA, portanto se trata de sítio prioritário para o desenvolvimento de projetos demonstrativos alinhados ao Programa Internacional de Reserva da Biosfera. Além disso, a área está em região considerada hotspot, pois possui altos níveis de biodiversidade e elevado grau de ameaça (MYERS et al., 2000). Estudos sobre o impacto de resíduos sólidos em regiões costeiras são, em geral, realizados com foco apenas nas praias e pouca atenção tem sido dispensada aos ecossistemas de manguezal neste aspecto. Um dos fatores que mais contribuem para a degradação dos manguezais é a chegada desses resíduos em grande quantidade. O descarte de resíduos ocorre em sua maior parte (80 a 90\%) concentrado em estuários e em águas marinhas costeiras (ARAÚJO e COSTA, 2007). Outro aspecto relevante para a realização dessa ação é o socioambiental e econômico. Há comunidades tradicionais de pescadores/catadores de caranguejo que não podem atuar no período de Defeso, tendo como exemplo o do caranguejo Uçá (Ucides cordatus) - Lei $\mathrm{n}^{\circ}$ 11.959, de 29 de junho de 2009. Por outro lado, existe o plano nacional de Resíduos Sólidos, Lei 12.305. No caso, associar a coleta desse material relacionando-a a Políticas Públicas de

\footnotetext{
${ }^{2}$ http://www.mma.gov.br/pol\%C3\%ADtica-de-res\%C3\%ADduos-s\%C3\%B3lidos 12

${ }^{3}$ http://www.planalto.gov.br/ccivil 03/_Ato2004-2006/2006/Dnn/Dnn10775.htm
} 
Educação Ambiental, demonstrando para a sociedade a perda de matéria prima (recicláveis) e o impacto que esse passivo ambiental (recicláveis) está causando em Unidades de Conservação, além da perda da sustentabilidade dos catadores/pescadores constituiu uma inovação na área de desenvolvimento sustentável. Além disso, oferecer uma renda alternativa para os participantes, para o período de limpeza do manguezal.

Enfim, é de conhecimento geral a existência de pressão antrópica nas áreas protegidas em remanescentes de áreas de manguezal. Um dos maiores problemas observados com o crescimento urbano nos ambientes costeiros é o acúmulo de resíduos. A Operação LIMPAOCA consiste numa ação piloto que se propõe ajudar na conservação dos recursos naturais envolvendo diferentes setores da sociedade, em especial, as comunidades de pescadores e catadores de caranguejo. Tem como objetivo também obter resultados qualiquantitativos a partir das coletas de resíduos sólidos nessa região.

\section{MATERIAL E MÉTODOS}

A Estação Ecológica da Guanabara tem uma superfície de 1.935 ha e seu perímetro é de $21,5 \mathrm{~km}$, estando localizada em dois municípios, Guapimirim (58\%) e Itaboraí (42\%). A Figura 1 ilustra a área de atuação dos participantes da Operação LIMPAOCA.

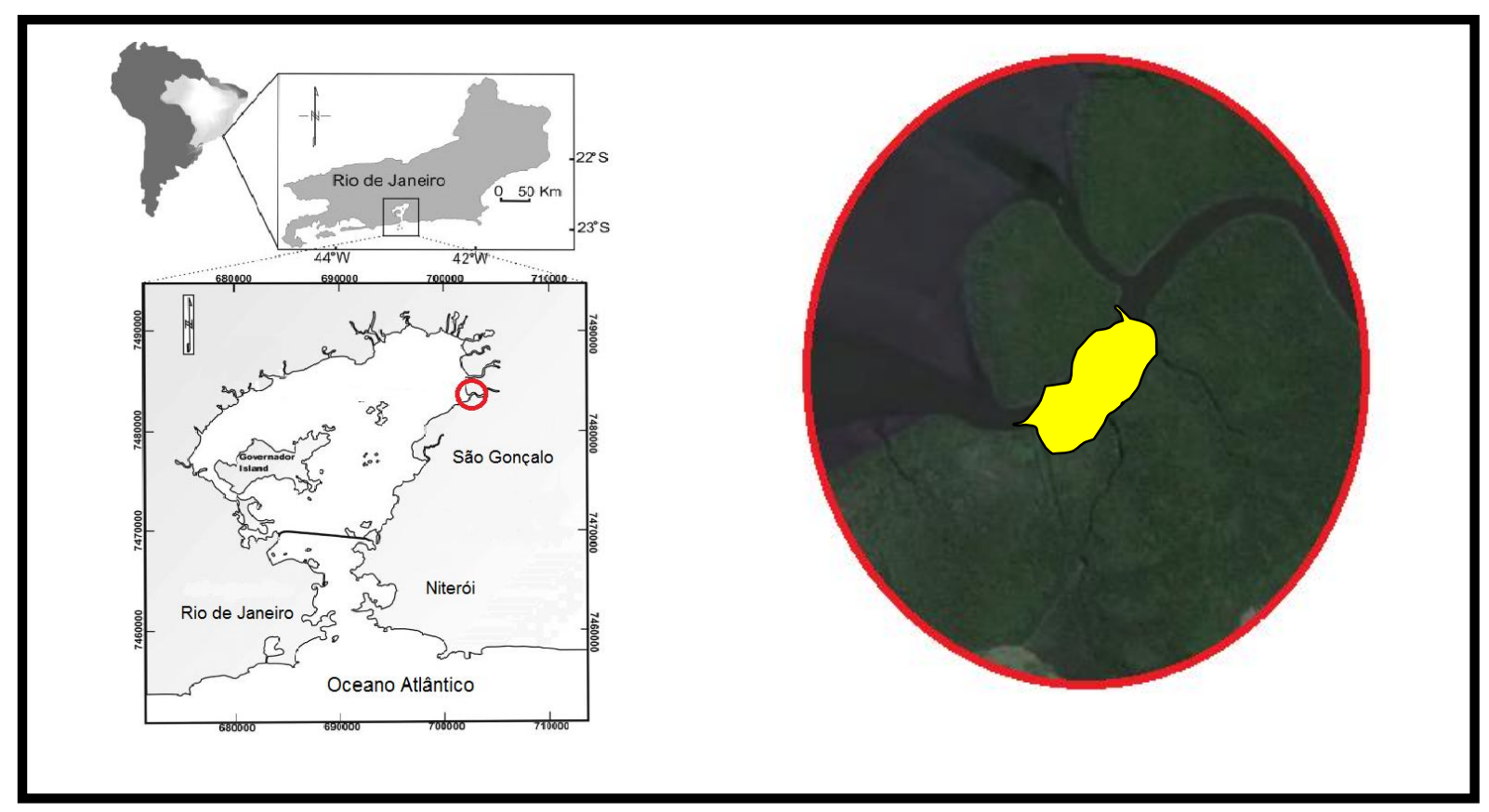

Figura 1: Localização da área da Operação LIMPAOCA.

$\mathrm{Na}$ área do ecossistema manguezal da ESEC Guanabara foram realizadas coletas de recicláveis nos seguintes dias: 10, 11, 17, 18, 24 e 25 de Fevereiro e 11, 17, 18, 25 e 31 de Março de 2014. A atividade ocorreu das 7 às 12 horas, sendo que para efeito de cálculo de coleta, só foram contabilizadas duas horas de atividade exclusiva (Figura 2). 


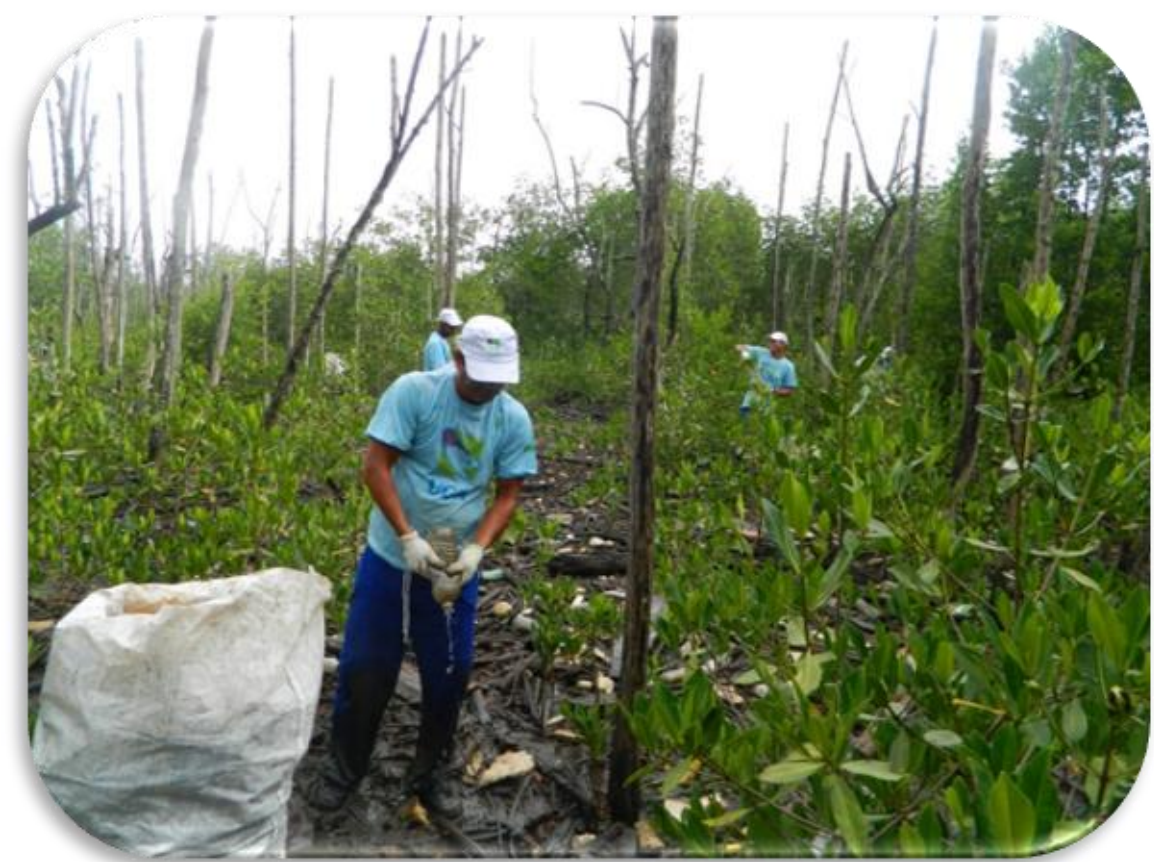

Figura 2: Momento de coleta em área da ESEC Guanabara.

As outras 3 horas foram ocupadas com o transporte do pessoal envolvido (13 catadores de caranguejo e pescadores, 2 biólogos), do resíduos, com a etapa de triagem e pesagem do produto da atividade e na retirada do material coletado para a Praia de São Gabriel, São Gonçalo (Figuras 3 e 4).
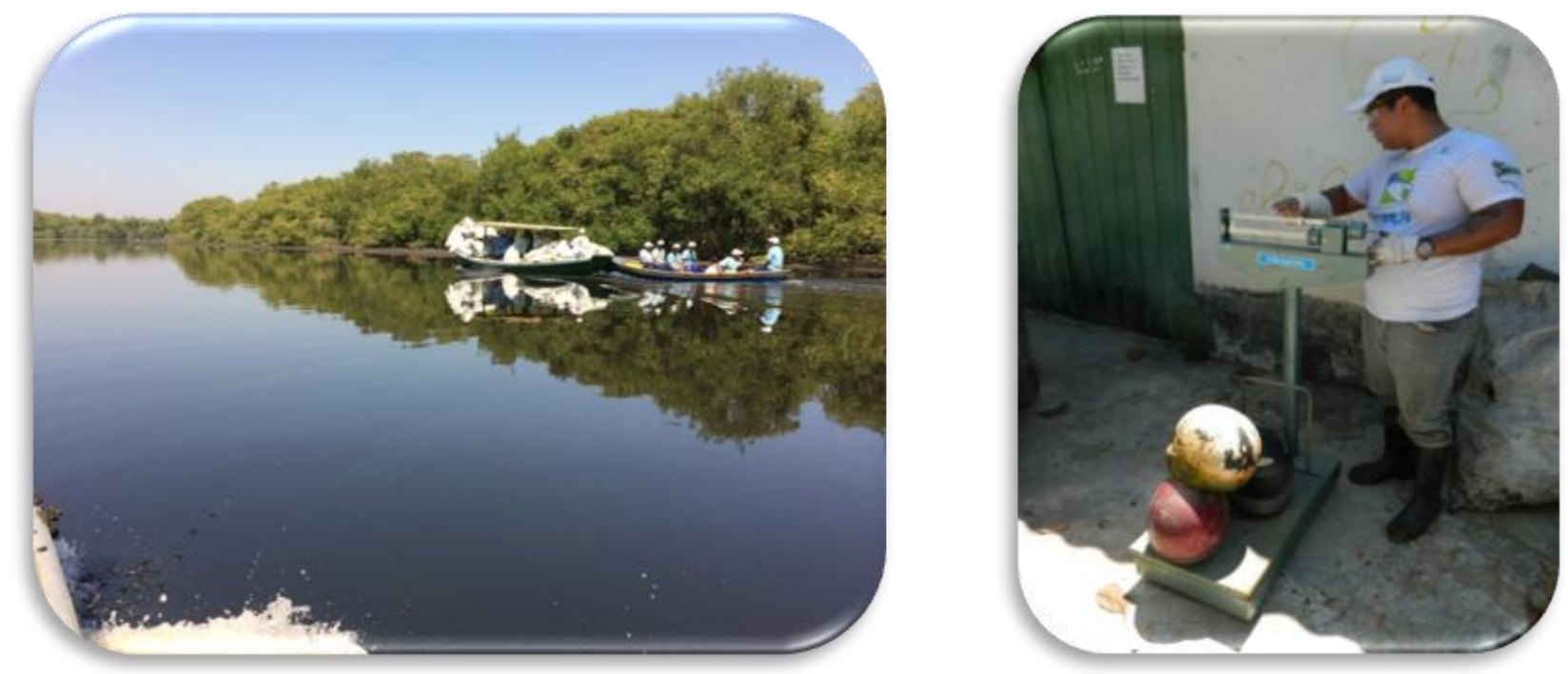

Figuras 3 e 4: Retorno à Praia de São Gabriel e triagem e pesagem do material coletado.

Os participantes da ação se concentravam na Praia de São Gabriel, município de São Gonçalo e, após o embarque rumavam, costeando pelo lado leste da Baía de Guanabara, para o município de Itaboraí, em área da ESEC Guanabara, na ilhota da foz do Rio Guaxindiba. 
Após o fornecimento dos equipamentos de proteção individual (EPIs) iniciavam a coleta de resíduos sólidos (Figura 5).

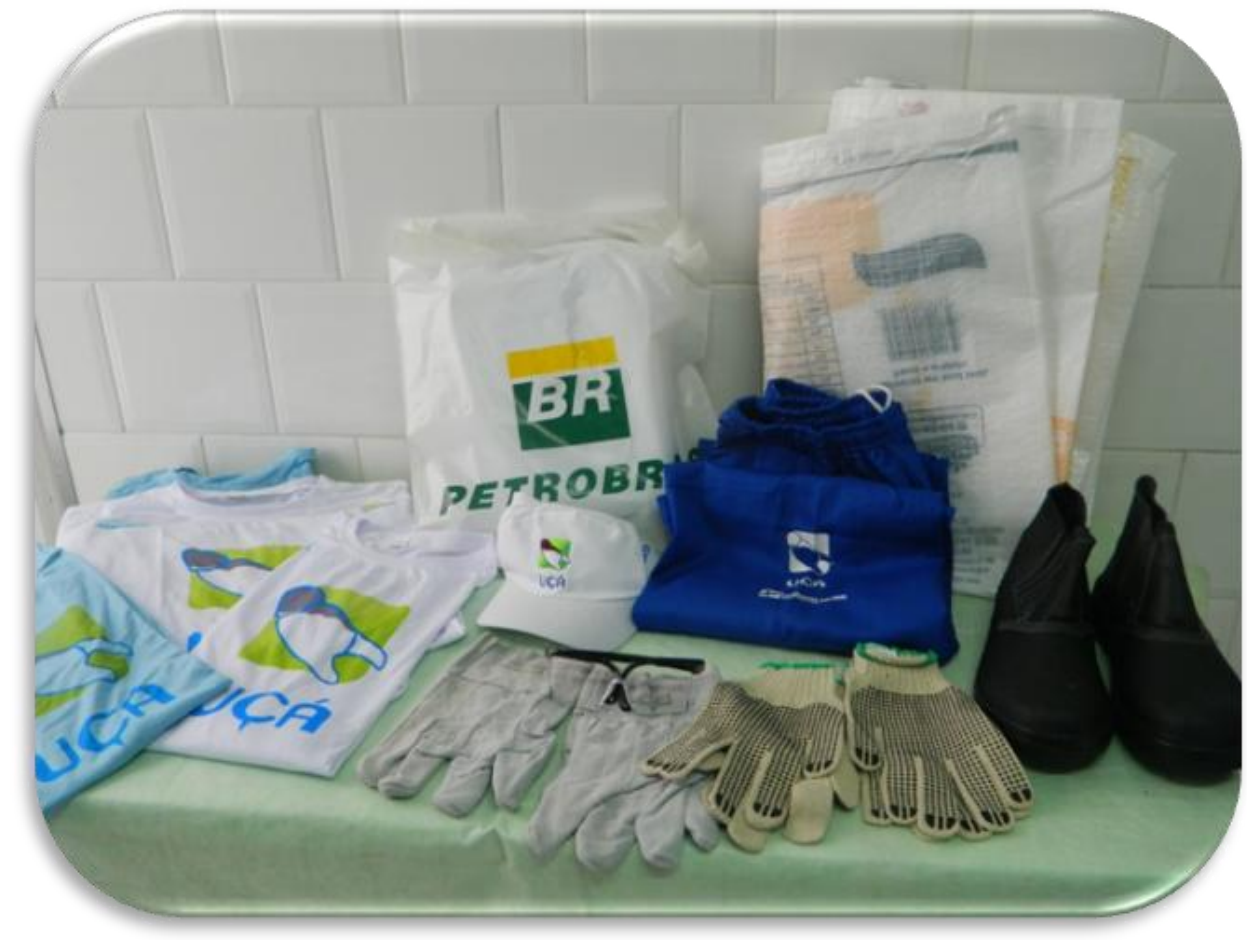

Figura 5: Conjunto de EPIs que os participantes utilizaram nas coletas da Operação LIMPAOCA.

A concentração dos resíduos foi na Praia de São Gabriel Bairro/Ilha de Itaoca, em São Gonçalo, onde foi feita a triagem e pesagem do material. Em parceria com a Secretaria Municipal de Meio Ambiente de São Gonçalo (Figura 6) o material era transportado para a sua destinação final correta, por ser inviável economicamente sua utilização.

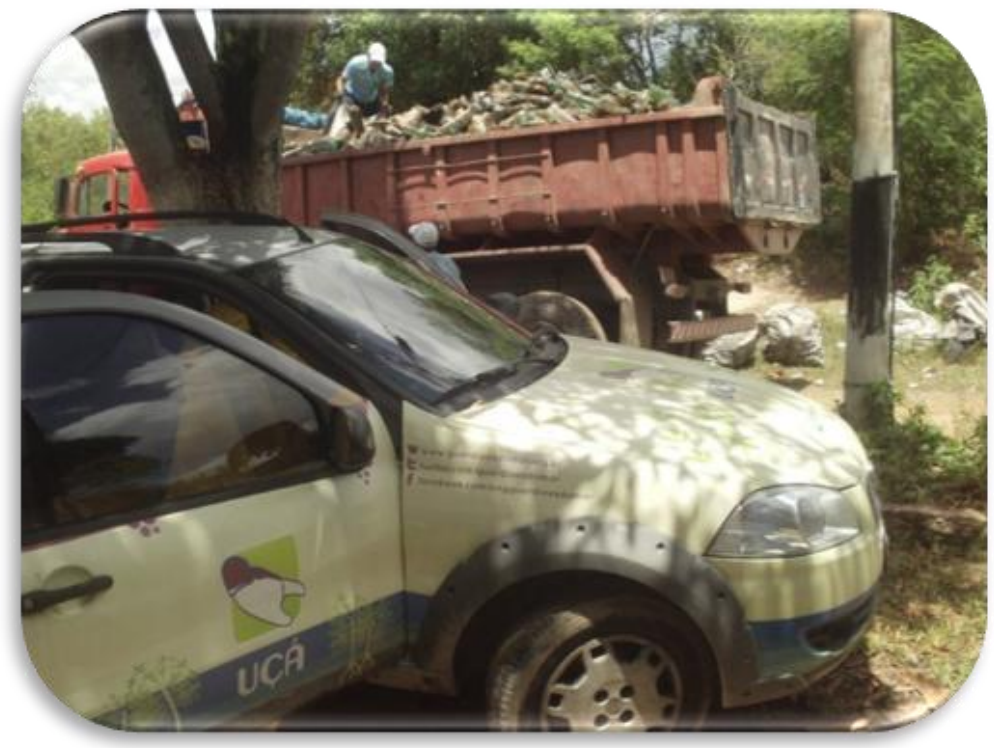

Figura 6: Etapa de carregamento dos recicláveis recolhidos do mangue para transporte ao seu destino final correto. 
Para os cálculos do Balanço Ecológico foi arbitrada a utilização das maiores relações de valoração ambiental da reciclagem, disponíveis na bibliografia, pois não há consenso que indique um único valor e, como a intenção é demonstrar a importância do reciclável, foi arbitrado desta forma. O Balanço Ecológico é uma Tecnologia Social registrada ${ }^{4}$.

Para o grupo de plásticos, todos os tipos de embalagens, brinquedos e diferentes composições, até mesmo pneus fizeram parte. No de vidros, todos os tipos de vasilhas e lâmpadas, de todas as cores. No de isopor foi estimado $2 \%$ de composição equivalente ao plástico, sendo este calculado como tal também. Quanto ao metal não foi feita distinção entre latinhas de alumínio e outros. Por fim, o grupo de couro e afins, o mais heterogêneo, onde $70 \%$ era composto de sapatos (30\% desse peso foi calculado como plásticos). Além disso, foram encontrados bichos de pelúcias, sofás, colchões e afins só tiveram seu peso valorado.

Para os dados econômicos relativos à valoração do material coletado foram utilizadas informações fornecidas pela Cooperativa de Catadores de Materiais Recicláveis de São Gonçalo, RECOOPERAR (CNPJ - 08.876.244/0001-44), de fevereiro de 2014.

\section{RESULTADOS E DISCUSSÃO}

Com uma coleta exclusiva de 22 horas por 13 pescadores/catadores de caranguejo, sem levar em conta a extensão da área de atuação, podemos inferir coleta diária de 129,5 $\mathrm{kg} / \mathrm{hora} / 13$ participantes e média de $9,9 \mathrm{~kg} /$ coletor.

A Figura 7 e a Tabela 1 apresentam os valores finais de cada grupo de classificação, sendo o total geral de $2.850 \mathrm{~kg}$, para 22 horas exclusivas para coleta de recicláveis. Assim como em Cordeiro (2006), o grupo dos plásticos foi o que predominou. O grupo do isopor seguiu de longe o de plásticos, mas, devido a seu grande volume e baixo peso, os $300 \mathrm{~kg}$ de material tornam-se muito significativos. Vidro, com $100 \%$ de lâmpadas, foi o terceiro colocado seguido do grupo mais heterogêneo, couro e afins. Por fim os metais, sendo composto por pequenas peças e latinhas. Belarmino et al. (2014) mencionaram que áreas de manguezal são ambientes extremamente sensíveis e propensos ao acúmulo de resíduos sólidos, principalmente em regiões com presença de usuários. No nosso caso, o rio Guaxindiba, corta uma extensa zona com população crescente e com baixo índice de infraestrutura na área de gestão de resíduos sólidos.

\footnotetext{
${ }^{4}$ http://rts.ibict.br/noticias/destaque-2/balanco-ecologico-e-ecoponto-social
} 


\section{kg}

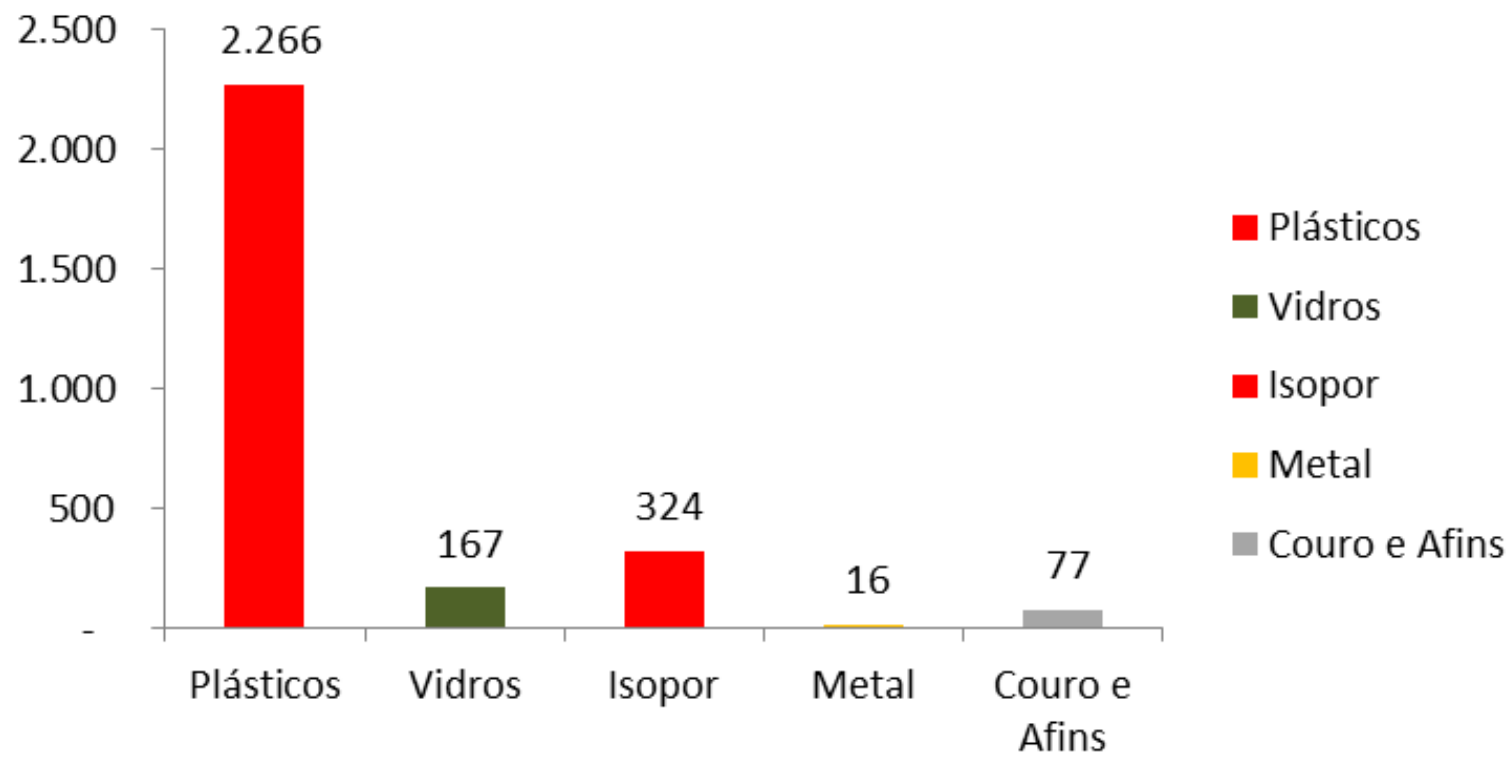

Figura 7: Valor final de cada grupo de material coletado na OPERAÇÃO LIMPAOCA.

Tabela 1: Valores em peso, por material e o percentual de cada grupo de resíduos sólidos.

\begin{tabular}{|l|r|r|}
\hline \multicolumn{1}{|c|}{ Material } & \multicolumn{1}{c|}{$\mathbf{k g}$} & $\%$ \\
\hline Plásticos & 2.266 & 79 \\
\hline Vidros & 167 & 6 \\
\hline Isopor & 324 & 11 \\
\hline Metal & 16 & 1 \\
\hline Couro e Afins & 77 & 3 \\
\hline Total & $\mathbf{2 . 8 5 0}$ & $\mathbf{1 0 0}$ \\
\hline
\end{tabular}

Assim como Coelho et al. (2007), que encontraram 65\% de plásticos, na Operação LIMPAOCA foram contabilizados 79\%, desse material. Em um estudo realizado na Angra de Thane, em Mumbai, os plásticos foram o grupo majoritário em diferentes áreas de estudo (SINGARE, 2012). Vieira et al. (2013), num estudo temporal de descarte de resíduos sólidos no manguezal de Ratones, em Florianópolis, o plástico representou $80 \%$ do material encontrado, corroborando com os demais autores.

Se todo o material coletado nos manguezais, durante a Operação LIMPAOCA, tivesse sido alvo de coleta seletiva não teriam sido desperdiçados no ambiente $\mathrm{R} \$ 4.425,75$. Tendo como exemplo a comercialização da Cooperativa ReCooperar, que vendeu o metal em fevereiro a $\mathrm{R} \$ 7,00 / \mathrm{kg}(16 \mathrm{~kg}$ coletados * $\mathrm{R} \$ 7,00=\mathrm{R} \$ 112,00)$, o PET a $\mathrm{R} \$ 1,90 / \mathrm{kg}(2.266 \mathrm{~kg}$ 
coletados $* \mathrm{R} \$ 1,90=\mathrm{R} \$ 4.305,40)$ e o vidro a $\mathrm{R} \$ 0,05 / \mathrm{kg}(167 \mathrm{~kg}$ coletados* $\mathrm{R} \$ 0,05=\mathrm{R} \$$ $8,35)$.

Se o plástico e isopor fossem coletados seletivamente não teriam sido desperdiçados no ambiente $2.590 \mathrm{~kg}$ de petróleo. No caso do vidro, a perda foi de $217 \mathrm{~kg}$ de areia, sua matéria prima. Isso sem falar nos recursos humanos envolvidos na cadeia produtiva da reciclagem desses materiais, incluindo a água, disponibilidade de $\mathrm{CO}_{2}$ para a atmosfera, árvores de manguezais, animais desse ecossistema, incluindo os caranguejos Uçás que disputam espaço com os resíduos para se perpetuarem, além dos catadores de caranguejos que tiram seu sustento desse ambiente.

A Prefeitura de Vitória/ES (2005) relatou ação similar em área de manguezal, também no período de Defeso do caranguejo, contudo não apresentou mais informações nos anos posteriores.

Segundo WARAT (2000, apud BATISTA, 2009) os membros de nossa sociedade devem entender que o direito do amanhã deve ser ético e legalmente protegido sendo um direito fundamental para as próximas gerações.

\section{CONCLUSÕES}

A Operação LIMPAOCA foi realizada com objetivo de contribuir com a limpeza de Unidades de Conservação em áreas de manguezal, propiciando a integração de diferentes setores da sociedade, operacionalizando a PNRS e a melhoria de qualidade ambiental em APPs.

Os resultados quantitativos dessa ação demonstraram a necessidade de sua realização periódica, aliada a ações de Educação Ambiental, para que em algum tempo futuro ela não seja mais necessária.

Ações como a Operação LIMPAOCA, se transformadas em Políticas Públicas impedirão que petróleo, na forma de plásticos, areia, na forma de vidros, bauxita, na forma de latinhas, entre outros recursos naturais, não mais serão perdidos. Além disso, árvores e animais não precisarão disputar espaço como os resíduos descartados incorretamente.

A Operação LIMPAOCA tem um caráter inovador, por se tratar de ação de Política Pública, com abordagem socioeducativa (PNEA) em área de Unidade de Conservação, nesse caso, Federal.

\section{CONSIDERAÇÕES FINAIS}

O Ministério do Meio Ambiente, por meio do Departamento de Educação Ambiental da Secretaria de Articulação e Cidadania Ambiental, conferiu a "Operação LIMPAOCA" o Certificado de Prática de Referência EducaRES. Tal registro foi de acordo com o Edital n ${ }^{\circ} 2$ de julho de 2014, e, mediante os critérios de:

- Caráter inovador; 
- Apresentar condições de reaplicabilidade da experiência;

- Utilizar as experiências, conhecimentos, metodologias e técnicas que sirvam de referências para projetos similares;

- Por possuir possibilidade de continuidade e/ou geração de processos contínuos de Educação Ambiental e/ou Comunicação Social em Resíduos Sólidos;

- Por ter abordagem de gestão integrada em suas múltiplas dimensões e relações complexas em diferentes escalas, envolvendo aspectos ecológicos, legais, políticos, sociais, econômicos, científicos e culturais;

- Por apresentar coerências entre os princípios e as ações;

- Ter tido desafios enfrentados e aprendizado obtido com erros e acertos; e

- Ter abrangência territorial conforme os princípios e práticas de Educação Ambiental e Comunicação Social crítica e emancipatória.

\section{AGRADECIMENTOS}

Ao Biólogo Wendell Gomes do Amaral.

\section{BIBLIOGRAFIA}

ARAÚJO, M. C. B.; COSTA, F. M. An analysis of the riverine contribution to the solid wastes contamination of an isolated beach at the Brazilian Northeast. Management of Environmental Quality: An International Journal, v. 18 n. 1. P. 6-12. 2007a.

ARAÚJO, M. C. B; COSTA, M. Visual diagnosis of solid waste contamination of tourist beach: Pernambuco, Brazil. Waste Management, vol. 27 , n. 6, p. 833-839. 2007b.

BATISTA, A. D. Meio Ambiente: Preservação e Sustentabilidade. Revista EPeQ/Fafibe, vol. $1,1^{\text {a }}$ ed., nov. 2009.

BElarminO, P. H. P., SILVA, S. M., RUFENER, M. C., ARAÚJO, M. C. B. Resíduos sólidos em manguezal no rio Potengi (Natal, RN, Brasil): relação com a localização e usos. Revista de Gestão Costeira Integrada, v. 14, n. 3, p. 447-457, 2014.

COElHO, A. C., COSTA, M. M. Ações de conservação e coleta de resíduos sólidos no manguezal do araçagy, Ilha de São Luís, Maranhão, Brasil. Apresentado no XIV Congresso Latino-Americano de Ciências do Mar - XIV COLACMAR, Balneário Camboriú (SC/Brasil), 30 de Outubro a 04 de Novembro de 2011.

COELHO, A. C. P., PAIXÃO V. M., OLIVEIRA T. S., RIBEIRO, CARVALHO-NETA, R. N. F. Impactos Causados por tensores de origem antrópica no manguezal do Araçagy - Ilha de São Luís - MA. Anais do VIII Congresso de Ecologia do Brasil, 23 a 28 de Setembro de 2007, Caxambu - MG. 
MYERS, N., MITTERMEIR, R. A., MITTERMEIR, C. G., FONSECA, G. A. B. E KENT, J. Biodiversity hotspots for conservation priorities. Nature. v. 403. 24 de fevereiro 2000.

PREFEITURA DE VITÓRIA. Projeto de educação Ambiental - MANGUE VIVO - Ação Integrada de Limpeza do manguezal. Vitória - E S. pp. 16. Agosto, 2005.

SINGARE, P. U., Study of Some Major Non-Biodegradable Solid Wastes Along Thane Creek of Mumbai. World Environment, v. 2, n. 3, p. 24-30, 2012.

VASQUES, R. O., TONINI, W. C. T., CUEVAS, J. M., SANTOS, D. F., FARIA, T. A., FALCÃO, F. C., SIMÕES D. R., BATISTA, R. L. G., COUTO, E. C. G. Utilização das Áreas de Manguezais em Taipús de dentro (Maraú, Sul da Bahia). Revista da Gestão Costeira Integrada, v. 11, n. 2, p. 155-161, 2011.

VIEIRA, B. P., DIAS, D., NAKAMURA, E. M., ARAI, T. I., HANAZAKI, N., Is there temporal variation on solid waste stranding in mangroves? A study in Ratones mangrove, Florianopolis, Brazil. Biotemas, v. 26, n. 1, p. 79-86, Março de 2013.

VIEIRA, B. P.; DIAS D.; HANAZAKI N. Homogeneidade de Encalhe de Resíduos Sólidos em um Manguezal da Ilha de Santa Catarina, Brasil. Revista da Gestão Costeira Integrada, v. 11, n. 1, p. 21-30, 2011.

\section{SITES CONSULTADOS}

< http://www.mma.gov.br/pol\%C3\%ADtica-de-res\%C3\%ADduos-s\%C3\%B3lidos > Acesso em: 12/04/15

< http://www.planalto.gov.br/ccivil_03/_Ato2004-2006/2006/Dnn/Dnn10775.htm > Acesso em: 20/04/2015

< http://rts.ibict.br/noticias/destaque-2/balanco-ecologico-e-ecoponto-social > Acesso em: 28/04/2015. 